ECCOMAS

Proceedia
COMPDYN 2021

$8^{\text {th }}$ ECCOMAS Thematic Conference on Computational Methods in Structural Dynamics and Earthquake Engineering M. Papadrakakis, M. Fragiadakis (eds.)

\title{
TOWARDS THE DEVELOPMENT OF A COMPREHENSIVE FRAMEWORK FOR LIFE CYCLE COST ANALYSIS OF BRIDGES SUBJECTED TO MULTIPLE HAZARDS
}

\author{
S. Sacconi ${ }^{1}$, L. Ierimonti ${ }^{1}$, I. Venanzi ${ }^{1}$ and F. Ubertini ${ }^{1}$ \\ ${ }^{1}$ Department of Civil and Environmental Engineering of University of Perugia \\ Via G. Duranti, 93, 06125 Perugia, Itlay \\ e-mail: stefano.sacconi@collaboratori.unipg.it; laura.ierimonti@unipg.it; ilaria.venanzi@unipg.it; \\ filippo.ubertini@unipg.it
}

\begin{abstract}
Life-cycle cost analysis (LCCA) is used as a decision-making tool in the design phase to predict the expenses required over the lifetime of the bridge. The application of LCCA to bridges allows to consider different types of uncertainties such as those on loads, resistances, degradation and on the numerical modelling and structural response analysis. In this context, the present paper proposes a general framework for bridges' LCCA under multiple hazards based on the use of the PEER equation. It allows to account for the random nature of hazards and for structural and modelling uncertainties, considering in a unified manner different hazards concurring to damage occurrence. The approach is for the first time applied to cost and fragility analysis of bridges subjected to fatigue, highlighting the possibility of treating the problem of fatigue damage estimation with an approach similar to the one currently adopted for damage induced by other hazards, like earthquake and wind. Starting from the knowledge of the traffic load model, the gross vehicles weight is assumed as intensity measure (IM) and a fatigue damage index calculated through the Palmgren-Miner's rule is adopted as engineering demand parameter (EDP). The damage accumulation is evaluated by considering the time dependency of the fatigue damage index. The framework is applied to the case study of a composite steel-reinforced concrete multi-span roadway bridge located in central Italy. The evolution over time of the probability of failure and the life-cycle costs due to fatigue damage induced by heavy traffic loads are investigated.
\end{abstract}

Keywords: Life cycle cost, PEER equation, multi hazard analysis, fatigue damage. 


\section{INTRODUCTION}

The correct definition of a life-cycle cost model for a bridge requires the preliminary selection of the limit states that could lead to bridge damage or collapse. The loads acting on the bridge are of different nature (earthquake, wind, traffic, degradation) and each one of them can lead to the achievement of more than one limit state. The main limit states which are taken into consideration in bridges are usually the achievement of the ultimate strength for bending and shear, the achievement of the serviceability limit states of deformation and stresses and the achievement of fatigue limit state [1]. In case of long-span bridges, aeroelastic limit states may also become important [2].

In this context, the fragility and cost assessment must be done exploiting a probabilistic approach to account for the random nature of hazards and for structural and modeling uncertainties, also considering in a unified manner different hazards concurring to damage occurrence. [3]. Several studies have addressed the problem of evaluating the expected life cycle cost of structures [4,5,6], including design applications of the main structure [7] and/or auxiliary damping systems $[8,9,10]$, which is related to the probability of failure calculated through the PEER convolution integral [11] or through a reliability analysis based on the calculation of the reliability index [12].

The objective of this paper is the estimation of lifetime costs of roadway bridges with specific focus on costs related to fatigue damage. The paper presents a general and comprehensive methodology accounting for multiple-hazards and several limit states, exploiting the PEER convolution integral to compute the probabilities of failure related to life-cycle costs. The application of the PEER equation is subordinate to the definition of a hazard curve for each type of load (i.e. earthquake, traffic) and to the selection of the engineering response parameters characterizing the damage limit states (forces, deformations, tensions and accelerations). The limit state conditions are expressed through fragility functions which lead to the determination of the probability that a damage threshold is exceeded [13].

The proposed framework is particularized to the case of bridges subjected to fatigue damage. The estimation of fatigue-related probability of failure using the PEER framework is a novelty in the scientific literature and allows to insert the evaluation of fatigue-damage induced costs in a comprehensive and unified framework for life-cycle cost assessment of bridges.

\section{METHODOLOGY FOR LCCA OF BRIDGES}

\subsection{General LCCA methodology in case of multiple-hazards}

The general formulation of the expected value of the total cost in the lifetime of a bridge, considering several hazard types and limit states at the same time, can be expressed through the following expression:

$$
\mathrm{E}\left[\mathrm{C}\left(\mathrm{L}_{\mathrm{t}}\right)\right]=\mathrm{C}_{0}+\sum_{\mathrm{t}=1}^{\mathrm{L}_{\mathrm{t}}}\left[\frac{\mathrm{C}_{\mathrm{m}}(\mathrm{t})+\mathrm{C}_{\mathrm{i}}(\mathrm{t})}{(1+\mathrm{r})^{\mathrm{t}}}+\sum_{\mathrm{h}=1}^{\mathrm{H}} \sum_{\mathrm{j}=1}^{\mathrm{J}} \sum_{\mathrm{s}=1}^{\mathrm{S}} \frac{\mathrm{E}\left[\mathrm{C}_{\mathrm{j}, \mathrm{s}, \mathrm{h}}(\mathrm{t})\right]}{(1+\mathrm{r})^{\mathrm{t}}}\right]
$$

where $\mathrm{E}$ [.] denotes the expected value operator; $\mathrm{L}_{t}$ is the lifetime of the bridge expressed in years; $\mathrm{J}$ is the total number of the considered limit states; $\mathrm{S}$ is the total number of analyzed sections; $\mathrm{H}$ is the total number of the considered hazards; $\mathrm{C}_{0}$ is the initial cost of the bridge that includes the costs for design, testing, construction, terrain purchase and safety burdens; $E\left[C_{j, s, h}\right]$ is the expected value of the cost of the $\mathrm{j}$-th limit state being reached in the s-th section of the bridge and due to the h-th hazard, including cost of damage and repair; $\mathrm{C}_{\mathrm{m}}$ is the maintenance cost per year; $\mathrm{C}_{\mathrm{i}}$ is the inspection cost per year; $\mathrm{r}$ is the discount rate. 
The total expected normalized cost is evaluated through normalization of the Eq. (1) with respect to the initial cost $\mathrm{C}_{0}$ as follows:

$$
c\left(\mathrm{~L}_{\mathrm{t}}\right)=\mathrm{E}\left[\frac{\mathrm{C}\left(\mathrm{L}_{\mathrm{t}}\right)-\mathrm{C}_{0}}{\mathrm{C}_{0}}\right]=\sum_{\mathrm{t}=1}^{\mathrm{L}_{\mathrm{t}}}\left[\frac{c_{\mathrm{m}}(\mathrm{t})+c_{\mathrm{i}}(\mathrm{t})}{(1+\mathrm{r})^{\mathrm{t}}}+\sum_{\mathrm{h}=1}^{\mathrm{H}} \sum_{\mathrm{j}=1}^{\mathrm{J}} \sum_{\mathrm{s}=1}^{\mathrm{S}} \frac{\mathrm{E}\left[k_{\mathrm{j}, \mathrm{s}, \mathrm{h}}(\mathrm{t})\right]}{(1+\mathrm{r})^{\mathrm{t}}}\right]
$$

where $c_{\mathrm{m}}=\mathrm{C}_{\mathrm{m}} / \mathrm{C}_{0}, c_{\mathrm{i}}=\mathrm{C}_{\mathrm{i}} / \mathrm{C}_{0}$ and $k_{\mathrm{j}, \mathrm{s}, \mathrm{h}}$ can be defined as follows:

$$
\mathrm{k}_{\mathrm{j}, \mathrm{s}, \mathrm{h}}=\left\{\begin{array}{cc}
\frac{\mathrm{c}_{\mathrm{j}} \mathrm{P}_{\mathrm{j}, \mathrm{s}, \mathrm{h}}}{\mathrm{C}_{0}} & \text { if } \mathrm{P}_{\mathrm{j}, \mathrm{s}, \mathrm{h}}<\overline{\mathrm{P}} \\
\frac{\mathrm{c}_{\mathrm{r}}}{\mathrm{C}_{0}} & \text { if } \mathrm{P}_{\mathrm{j}, \mathrm{s}, \mathrm{h}}=\overline{\mathrm{P}}
\end{array}\right.
$$

where $c_{j}$ is the failure cost related to the $\mathrm{j}$-th limit state, $c_{r}$ is the repair cost per unit length, $\overline{\mathrm{P}}$ is the probability threshold beyond which the repair cost is required and $\mathrm{P}_{\mathrm{j}, \mathrm{s}, \mathrm{h}}$ can be evaluated by using the PEER convolution integral, as follows:

$$
\mathrm{P}_{\mathrm{j}, \mathrm{s}, \mathrm{h}}=\iint \mathrm{P}(\mathrm{DS} \mid \mathrm{EDP}) f(\mathrm{EDP} \mid \mathrm{IM}) f(\mathrm{IM}) \mathrm{dEDP} \mathrm{dIM}
$$

where IM is the intensity measure related to the h-th hazard; EDP is the engineering demand parameter at section s; DS is the damage state associated to the achievement of the $\mathrm{j}$-th limit state; $\mathrm{P}(\mathrm{DS} \mid \mathrm{EDP})$ is the fragility curve (the complementary cumulative distribution function of DS conditioned to the occurrence of EDP); $f(\mathrm{EDP} \mid \mathrm{IM})$ is the probability density function (PDF) of EDP conditional on IM; $f(\mathrm{IM})$ is the PDF of IM.

The earthquake and the traffic are the main hazards stressing a bridge. For seismic risk assessment, it is necessary to conduct a probabilistic analysis considering the site where the structure is located, the possible presence of nearby faults and the different magnitudes associated with the return period. By knowing this information, it is possible to determine the hazard curve that shows the variation of IM parameter versus the annual average of exceedance. In the earthquake case, the intensity measure (IM) can be defined as the spectral acceleration, the peak ground acceleration or the magnitude. The engineering parameters demand (EDPs) can be represented by internal forces, deformations, displacements or accelerations. The use of an EDP is specifically related to the analyzed limit state. For example, in the case of piers it is possible to use as EDP the displacement of the piers, which is closely linked to the bending and shear stresses that occur due to the seismic event.

\subsection{LCCA methodology for bridges subjected to fatigue limit state}

In this Section, the methodology is particularized to the LCC analysis of bridges subjected to fatigue damage due to traffic load.

The proposed methodology adopts as IM the gross vehicle weight (GVW). The traffic hazard curve, whose first derivative is the $f(\mathrm{IM})$ in the PEER equation, is specific for the analyzed bridge and represents the annual relative frequency of vehicles passages as a function of the GVW. It can be obtained following two different procedures:

1. exploiting information provided by the National Standards that give the annual traffic composition;

2. using monitoring data obtained from a Weight-In-Motion (WIM) system capable of detecting the total weights and the number of the vehicles that annually pass through the bridge.

The proposed methodology adopts the fatigue damage index (D) calculated through the Palmgren-Miner's rule, as EDP [14]: 


$$
\mathrm{D}=\sum_{\mathrm{i}} \frac{\mathrm{n}_{\mathrm{i}}}{\mathrm{N}_{\mathrm{i}}}
$$

where $n_{i}$ is the number of cycles associated with the stress range $\Delta \sigma_{i}$ and $N_{i}$ is the corresponding cycles to failure obtained from the S-N Wöhler curve [15]. The time histories of the internal forces and the corresponding stresses at the analyzed sections are determined from the knowledge of the influence line of each type of vehicle and using the rainflow cycle counting method [16].

Exploiting Eq. (4) it is possible to determine the annual probability of exceeding the fatigue limit state due to traffic load. The following steps are carried out for the computation of the PEER equation:

- partition of the GVW range, available from WIM data or from National Standards, in a set of intervals. Knowing the annual number of passages corresponding to the vehicles comprised in each subinterval, it is possible to determine a relative frequency diagram of GVW which is used to obtain the probability distribution of GVW, i.e., $f(\mathrm{IM})$ (Figure 1 (a));

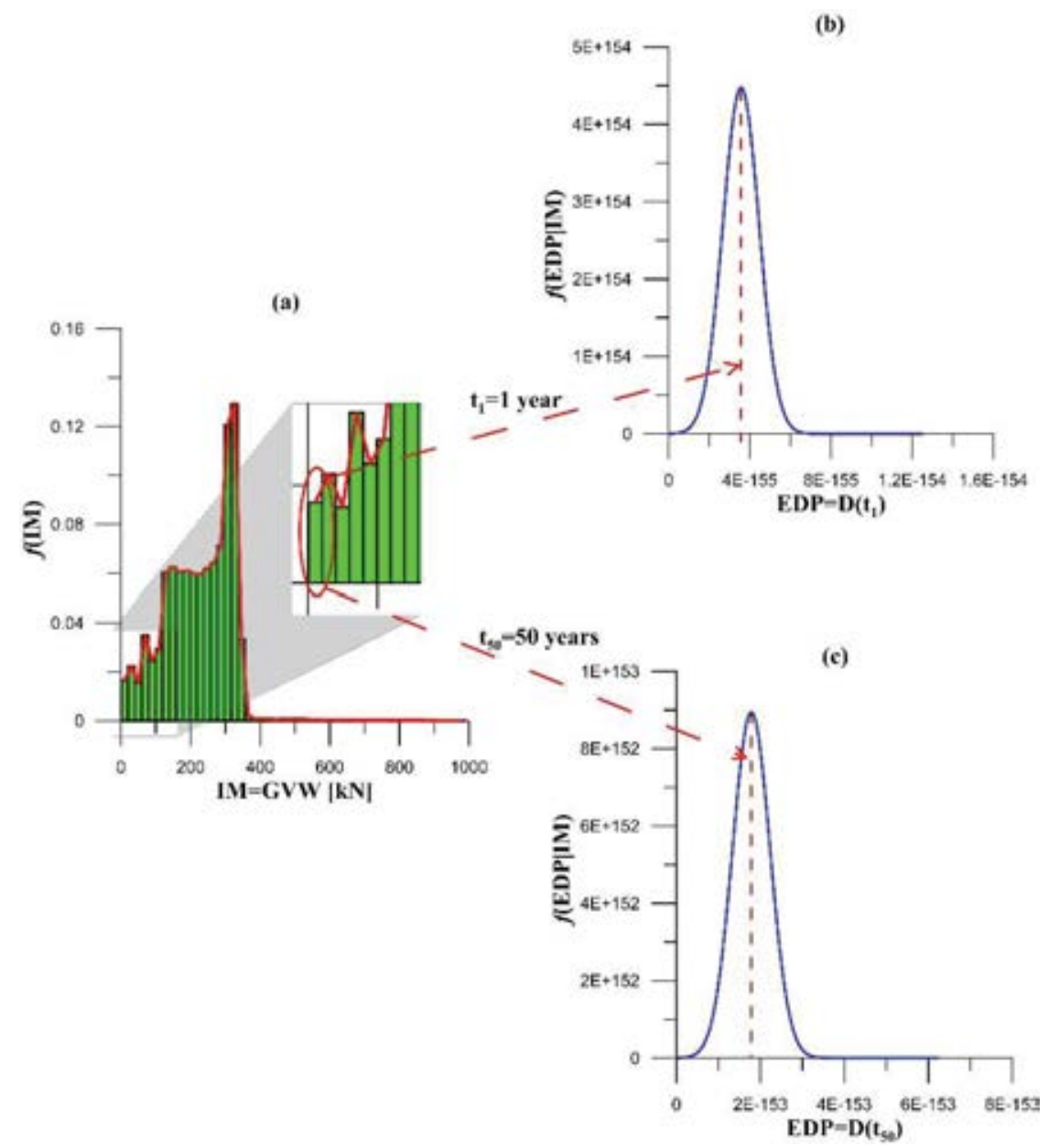

Figure 1. Probability density function of IM (a), probability density functions of EDP for different operating years: $t_{1}=1$ year $(b)$ and $t_{50}=50$ years $(c)$.

- for each k-th subinterval of GVW, a damage index $D_{k}$ is computed as the sum of the damage indices of the vehicles belonging to the k-th subinterval, exploiting Eq. (5). $\mathrm{D}_{\mathrm{k}}$ is assumed as the mean value of the EDP conditional on IM, $f(\mathrm{EDP} \mid \mathrm{IM})$. A normal distribution is adopted for $f(\mathrm{EDP} \mid \mathrm{IM})$, with mean value equal to $\mathrm{D}_{\mathrm{k}}$ and a coefficient 
of variation (COV) taken from literature, accounting for uncertainties in traffic load model characterization and response parameters estimation (Figure 1 (b-c)). To account for damage accumulation over time, the probability distribution of EDP is modified over years. In particular, for each k-th subinterval of GVW, the mean value of $\mathrm{D}$ at time $\mathrm{t}_{\mathrm{i}}$, is obtained as the sum of $\mathrm{D}_{\mathrm{k}}\left(\mathrm{t}_{\mathrm{i}-1}\right)$ and $\mathrm{D}_{\mathrm{k}}\left(\mathrm{t}_{\mathrm{i}}\right)$. Moreover, if the traffic model is constant with time $\mathrm{D}_{\mathrm{k}}\left(\mathrm{t}_{\mathrm{Lt}}\right)=\mathrm{L}_{\mathrm{t}} \cdot \mathrm{D}_{\mathrm{k}}\left(\mathrm{t}_{\mathrm{t}}\right)$;

- definition of the fragility curve P(DS|EDP); the fatigue damage occurs when the damage value D (calculated through Eq. (5)) equals its critical value $\mathrm{D}_{\text {crit: }}$ :

$$
\mathrm{D}_{\text {crit }}-\mathrm{D}=0
$$

Due to the random nature of fatigue damage, $\mathrm{D}_{\text {crit }}$ can be considered as a random variable with mean value equal to unity. Therefore, the fragility curve is determined by defining an uncertainty on the critical damage value distributed with a log-normal distribution, as shown in Figure 2.

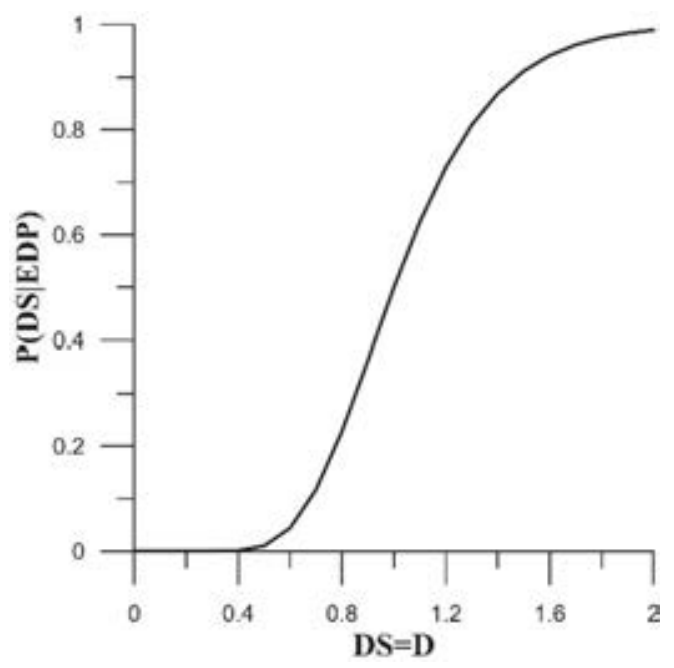

Figure 2. Fragility curve.

\section{THE CASE STUDY}

The proposed framework has been applied to a continuous steel-concrete composite highway bridge located in central Italy. The structure is 570 meters long and includes 10 spans of varying lengths, represented in Figure 3. The cross section consists of two double-T welded steel girders. The PEER convolution integral is calculated on 57 sections, uniformly spaced every 10 meters over the bridge length. The detail category considered for the fatigue limit state is a continuous longitudinal weld between the web and the flange of the girder.

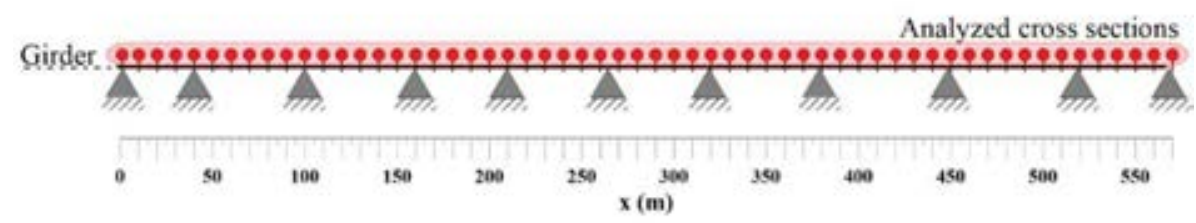

Figure 3. Schematic representation of the bridge with the indication of the analyzed cross sections. 


\subsection{Hazard model}

For the evaluation of the fatigue limit state it is necessary to probabilistically characterize the traffic model through the hazard curve. For the sake of demonstrating the influence of the traffic model on the LCCA results, the analyses have been carried out considering two different types of traffic hazard curves:

- the first hazard curve has been constructed from traffic data obtained from a WIM monitoring system located along the Interstate 80, Iowa, USA, known to the authors from a separate research study. The traffic hazard curve has been defined experimentally by choosing as the parameter that describes the load the GVW according to its annual frequency of exceeding. The traffic hazard curve obtained from WIM data is shown in Figure 4 (a);

- the second hazard curve has been obtained considering the Fatigue Load Model 4 used by the European Technical Standard (Eurocode 1 - Part 2) [17] for the estimation of fatigue damage on bridges (Figure 4 (b)). The Eurocode provides, for each one of the five vehicles specified in Fatigue Load Model 4 and for a specific type of road, the weight of the single axles and the percentage of the number of passages with respect to the total number of annual passages. The IM is the GVW calculated as the sum of the weights of the individual vehicle axles provided by the Eurocode. The total number of vehicles is assumed equal to the one provided by the WIM system, to consider the effect of the sole traffic distribution, being equal the traffic intensity.

(a)

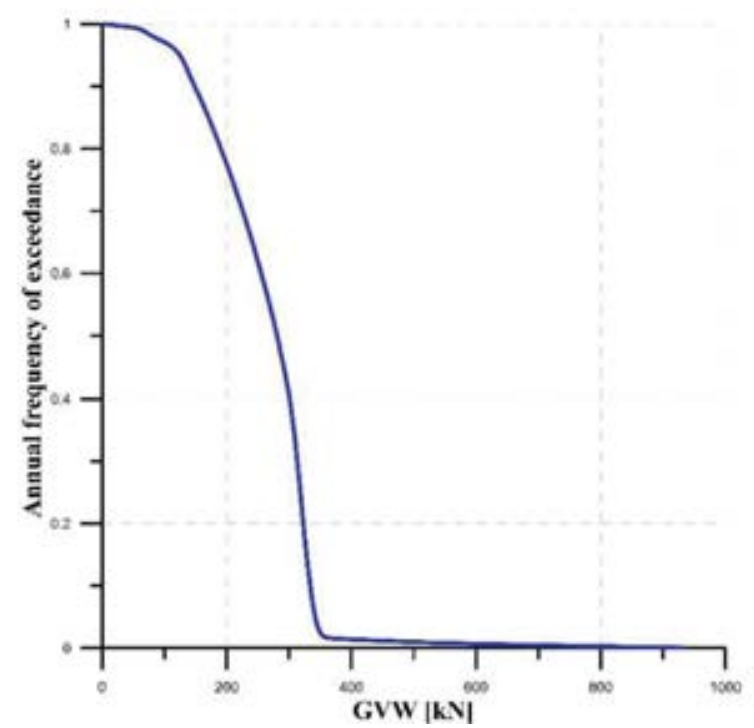

(b)

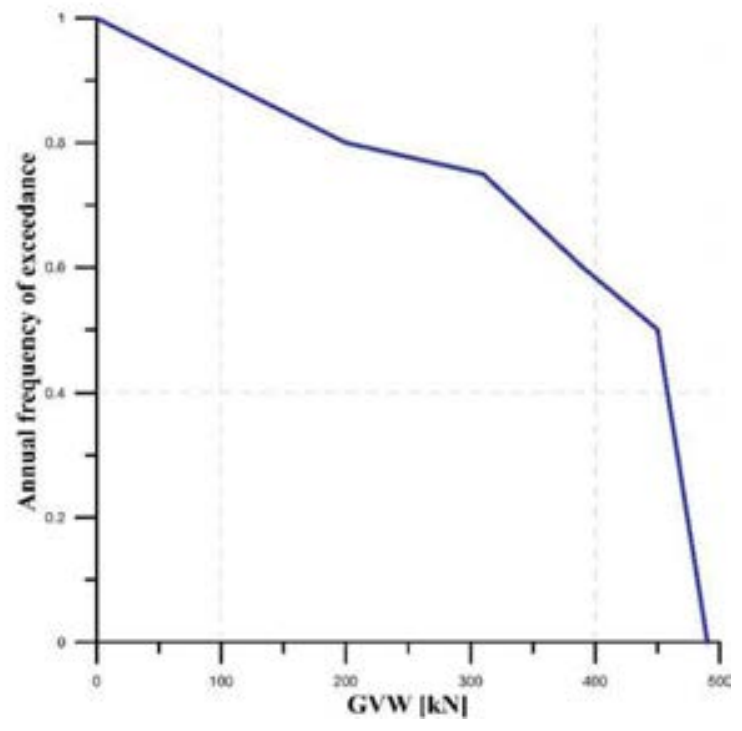

Figure 4 Traffic hazard curve obtained from WIM system (a) and from Eurocode (b).

It is assumed that the annual composition of traffic does not change over time, so the PDF(IM) is the same for all years. On the other hand, the value of the EDP changes over time due to the accumulation of damage.

\subsection{Fatigue damage assessment}

The calculation of the damage index $\mathrm{D}$ is done through Eq. (5), where $\mathrm{n}_{\mathrm{i}}$ is determined from WIM data in case of use of the monitoring system while $n_{i}$ is defined as a percentage of the total number of vehicle passage in the case of adoption of Eurocode Fatigue Load Model 4. In both 
cases, in addition to providing information regarding the total weight of the vehicles, the weight distribution of the axles and their spacing are provided. This information is necessary for the determination of the influence line which allows to evaluate the time histories of the internal forces and the corresponding stresses at the analyzed sections. The stress ranges are determined by the rainflow method [16] and the corresponding cycles to failure obtained from the S-N curve.

The damage index D calculated for each range of GVW is assumed to have a normal distribution with a $\mathrm{COV}=0.25$. The uncertainty assumed on the Palmgren-Miner damage accumulation rule $\left(\mathrm{D}_{\text {crit }}\right)$ is assumed to be lognormal distributed with mean 1.0 and $\mathrm{COV}=0.3$ [18].

Figure 5 shows the probability of exceeding the fatigue limit state over time of one of the most critical bridge sections (no. 43, at the midspan of the $8^{\text {th }}$ span), calculated by Eq. (4). Figure 5 (a) represents the probability calculated from the hazard traffic curve obtained from the WIM system and Figure 4 (b) shows the probability referred to the hazard traffic curve obtained from the Eurocode. The increase in probability over time is due to the accumulation of damage caused by the passage of vehicles across the bridge.

(a)

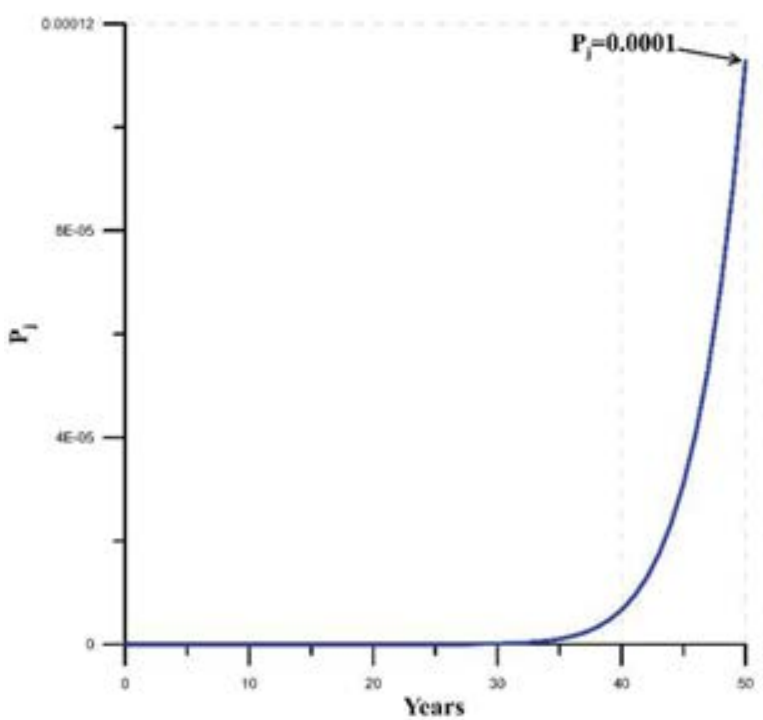

(b)

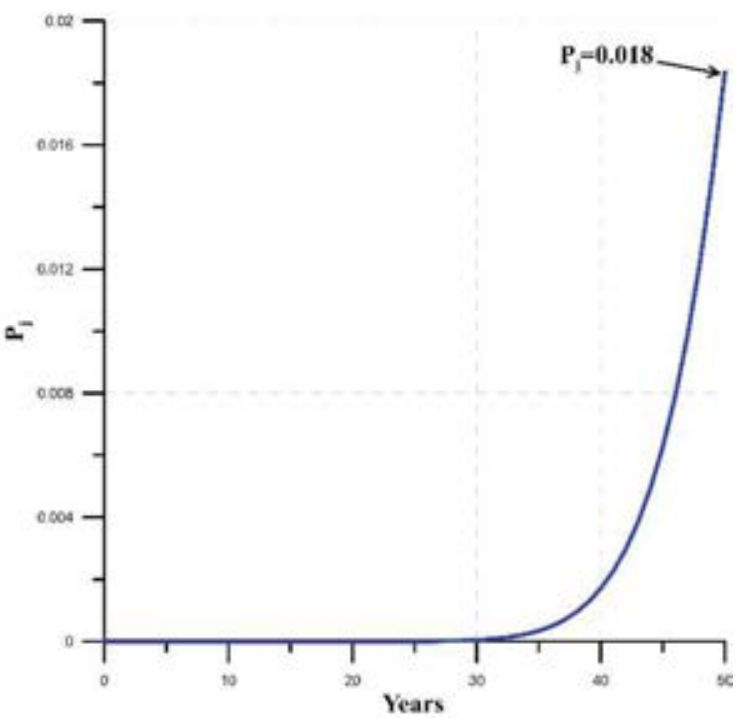

Figure 5 Probability of exceeding the fatigue limit state over the lifetime of the bridge in section no. 43 obtained using traffic model from WIM system (a) and from Eurocode (b).

\subsection{Life-cycle cost analysis}

LCCA is carried out by applying Eqs. (2-3). The initial cost $\mathrm{C}_{0}$ is taken from design documentation [12]. The maintenance $\operatorname{cost} \mathrm{C}_{\mathrm{m}}$ is considered as a percentage of the initial cost of the bridge. The annual percentage value is assumed to be equal to $1 \%$ [19]. The unit $c_{\mathrm{j}}$ can be computed as a percentage $v$ of the initial cost $\mathrm{C}_{0}[12]$, as follows:

$$
c_{\mathrm{j}}=v \mathrm{C}_{0}
$$

while the repair cost $c_{\mathrm{r}}$ is taken as the $10 \%$ of $c_{\mathrm{j}}\left(c_{\mathrm{r}}=0.1 c_{\mathrm{j}}\right)$. The coefficient $v$ is taken to be equal to 1.1 to account for demolition and disposal costs [12]. The annual inspection cost is defined through the price list of Italian National Autonomous Roads Corporation (ANAS) [20]. The cost items are summarized in Table 1 and Table 2. 


\begin{tabular}{ll}
\hline Cost item & Cost \\
\hline $\mathrm{C}_{0}[12]$ & $€ 4.084 .801$ \\
$\mathrm{C}_{\mathrm{m}}[19]$ & $€ 40.848,01$ \\
$\mathrm{C}_{\mathrm{i}}[20]$ & $€ 11.439,65$ \\
$c_{\mathrm{j}}[12]$ & $€ 4.493 .281,10$ \\
\hline
\end{tabular}

Table 1: Costs of the bridge.

\begin{tabular}{ll}
\hline $\mathrm{C}_{\mathrm{i}}$ & Cost \\
\hline Inspection of bridges and viaducts [20] & $15.52 € / \mathrm{m}$ \\
Inspection of piers [20] & $235.75 € / \mathrm{pier}$ \\
\hline
\end{tabular}

Table 2: Inspection Costs.

The discount rate is assumed equal to $r=0.05$ and the threshold of the probability beyond which a repair intervention is required is $10^{-2}$ [21].

Figure 6(a) illustrates the expected life cycle cost over time of the bridge normalized with respect to the initial construction costs (Eqs. (2-3)) and Figure 6(b) shows the corresponding cumulated probability of failure as a function of time by comparing the case in which the hazard traffic curve is obtained from the monitoring system and when it is obtained from the Eurocode. In the case of Eurocode, it can be noted the cost increase associated to the attainment of the probability threshold.

(a)

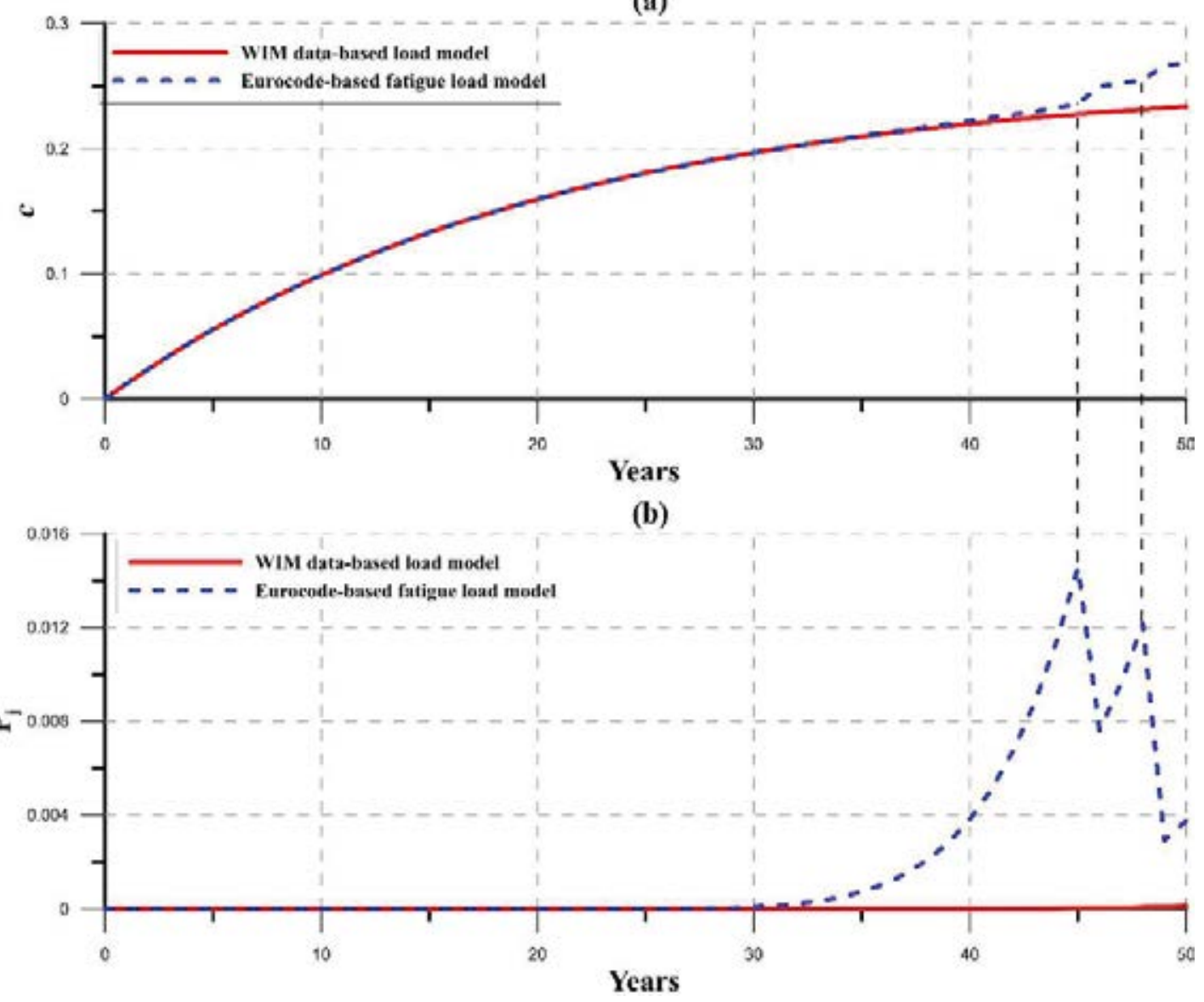

Figure 6 Expected normalized costs over the lifetime of the bridge (a) and the related probability (b). 
Since the choice of the probability distributions of EDP and $D_{\text {crit }}$ significantly influence the expected costs, parametric analyses have been carried out on the variations of the COVs of EDP and $D_{\text {crit. }}$ Figures 7 (a) and 7 (b) show the normalized expected cost, evaluated for different values of COV of $\operatorname{EDP}(0.25,0.5$ and 0.8$)$ for $D_{\text {crit }}$ lognormally distributed with mean 1.0 and $\mathrm{COV}=0.3$, for the case of Eurocode-based fatigue load model and WIM-based monitoring data load model, respectively. Figures 7 (c) and 7 (d) represent the normalized expected cost, evaluated with mean 1.0 and for different values of COV of $D_{\text {crit }}(0.1,0.2$ and 0.3$)$ and for a fixed value of COV of EDP equal to 0.8, for the case of Eurocode-based fatigue load model and WIM-based monitoring data load model, respectively. It is visible from Figures 7 (a-b) that the expected cost increases over time and is greater when the uncertainty on the EDP is equal to 0.8. On the other hand, Figures 7 (c-d) show that the cost is higher when the uncertainty on COV of $\mathrm{D}_{\text {crit }}$ equals 0.3 .

(a)

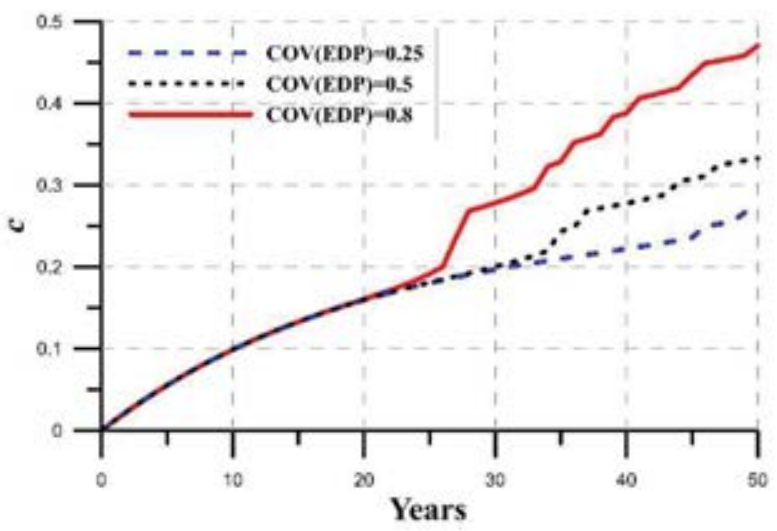

(c)

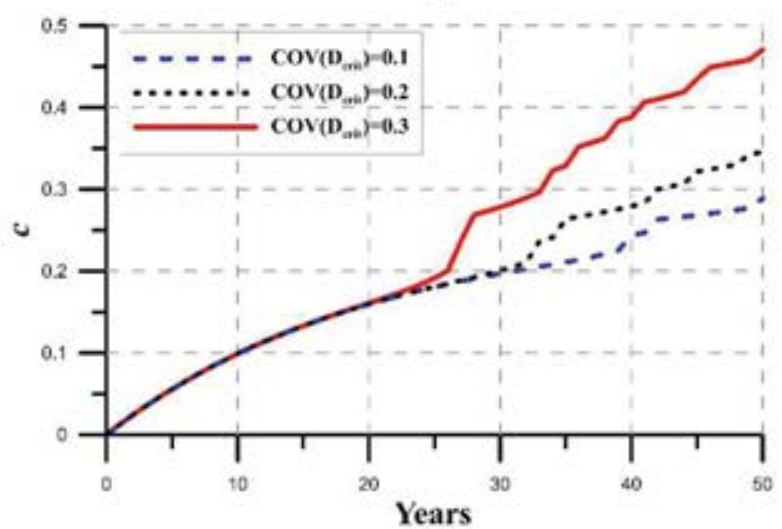

(b)

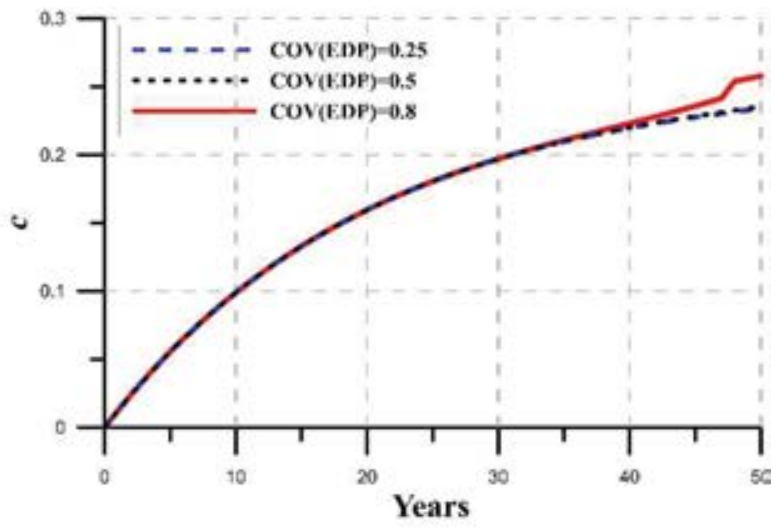

(d)

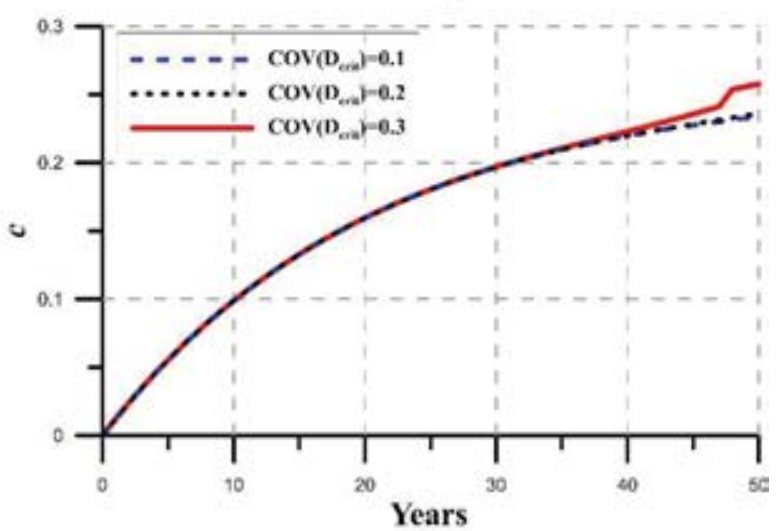

Figure 7 Expected normalized costs over the bridge's lifetime for different values of COV of EDP (a-b) and $\mathrm{D}_{\text {crit }}$ (c-d).

Figure 8 shows the results in terms of expected normalized costs (a-b) and the corresponding trends of the fatigue failure probabilities (c-d) considering COV of EDP equal to 0.8 (mean value equal to $\mathrm{D}$ ) and $\mathrm{D}_{\text {crit }}$ equal to 0.3 (mean value equal to 1.0 ). Figures 8 (a-c) are obtained with the Eurocode-based fatigue load model and Figures 8 (b-d) are obtained with the WIM data-based load model. In both cases it is possible to observe that the costs increase when the probability threshold is reached, as there is the need for a repair action. From results, it can also be noted that the Eurocode-based hazard traffic curve overestimates the cost with respect to the case in which the hazard curve is obtained from WIM data. 
(a)

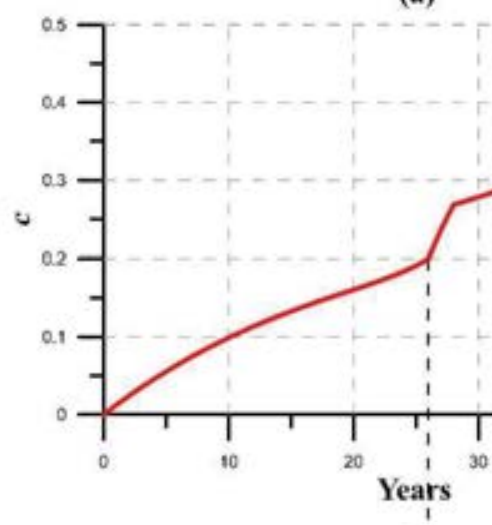

(c)

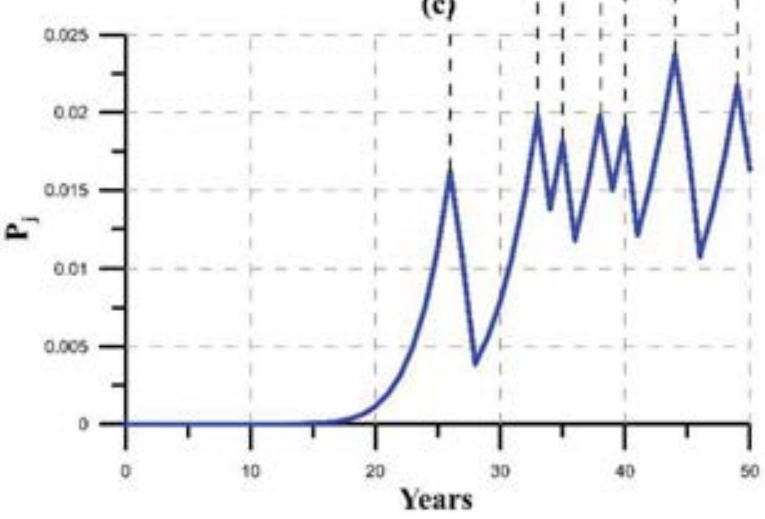

(b)

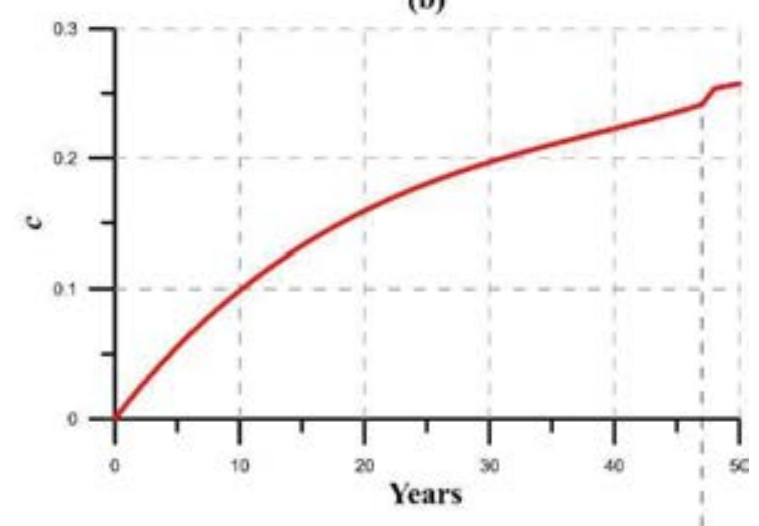

(d)

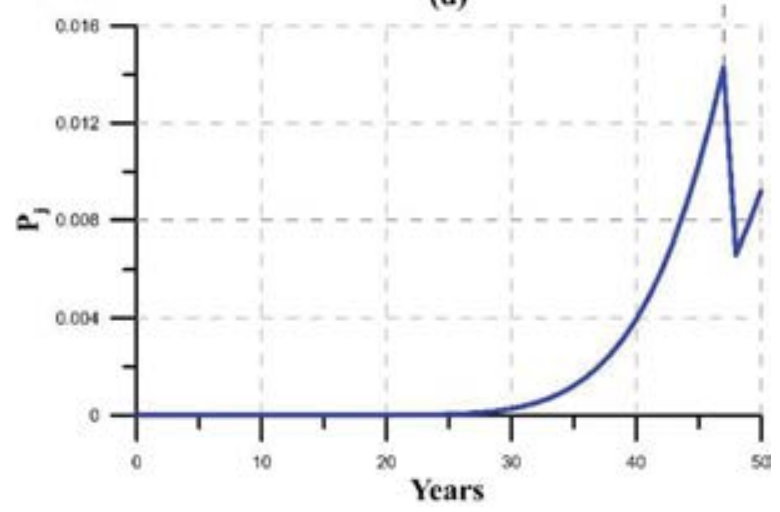

Figure 8 Expected normalized costs over the lifetime of the bridge (a-b) and the respective trends of the probabilities (c-d).

\section{CONCLUSIONS}

In this paper a general methodology for the computation of the expected total life-cycle cost of bridges is proposed, based on the PEER equation for failure probability estimation. The approach is for the first time applied to cost and fragility analysis of bridges subjected to fatigue, highlighting the possibility of treating the problem of fatigue damage estimation with an approach similar to the one currently adopted for damage induced by other hazards, like earthquake and wind. Starting from the knowledge of the traffic load model, the gross vehicles weight is assumed as IM and the fatigue damage index calculated through the PalmgrenMiner's rule is adopted as EDP. The damage accumulation is evaluated by considering the time dependency of the fatigue damage index.

The framework was applied to a continuous steel-concrete composite highway bridge located in central Italy by evaluating the fatigue limit state from the traffic loads defined by the Eurocode and obtained through a WIM monitoring system, for different probability distributions of the EDP and for different fragility models. The comparison between the fatigue failure probabilities and the life-cycle costs obtained with the two traffic models highlighted that the Eurocode-based hazard traffic curve overestimates the cost with respect to the case in which the hazard curve is obtained from WIM data, encouraging the adoption of traffic monitoring systems for a correct damage estimation. 


\section{AKNOWLEDGMENTS}

The authors gratefully acknowledge the support of the "Cassa di Risparmio di Perugia" Foundation, that funded this study through the Project "Development of an original life-cycle cost model for the optimal management of bridges and viaducts equipped with SHM systems" (Grant number 2019.0338.029), and the support of Brent Phares at Iowa State University and the Iowa Department of Transportation that provided the field monitoring system data.

\section{REFERENCES}

[1] A. C. Estes, D. M. Frangopol, Bridge lifetime system reliability under multiple limit states. Journal of Bridge Engineering, 6(6), 2001.

[2] F. Ubertini, Prevention of suspension bridge flutter using multiple tuned mass dampers. Wind \& Structures, 13(3), 235-256, 2010.

[3] K. M. Lee, H. N. Cho, Y. M. Choi, Life-cycle cost-effective optimum design of steel bridges. Journal of Constructional Steel Research, 60(11), 1585-1613, 2004.

[4] I. Venanzi, O. Lavan, L. Ierimonti, S. Fabrizi, Multi-hazard loss analysis of tall buildings under wind and seismic loads. Structure and Infrastructure Engineering, 14(10), 1295 1311, 2018.

[5] I. Venanzi, L. Ierimonti, L. Caracoglia, Life-cycle-cost optimization for the wind load design of tall building equipped with TMDs. Wind and Structures, 30(4), 379-392, 2020.

[6] S. H. Kim, M. S. Choi, K. I. Cho, S. J. Park, Determining the Optimal Structural Target reliability of a Structure with a Minimal Life-Cycle Cost Perspective. Advances in Structural Engineering, 16(12), 2013.

[7] L. Micheli, A. Alipour, S. Laflamme, Life-cycle-cost optimization of wind-excited tall buildings using surrogate models. Structural Design of Tall and Special Buildings, 30(6), e1840, 2021.

[8] L. Micheli, A. Alipour, S. Laflamme, P. Sarkar, Performance-based design with life-cycle cost assessment for damping systems integrated in wind excited tall buildings. Engineering Structures, 195, 438-451, 2019.

[9] L. Micheli, L. Cao, S. Laflamme, A. Alipour, Life-Cycle Cost Evaluation Strategy for High-Performance Control Systems under Uncertainties. Journal of Engineering Mechanics, 146(2), 04019134, 2020.

[10] S. Kleingesinds, O. Lavan, I. Venanzi, Life-Cycle cost-based optimization of MTMDs for tall buildings under multiple hazards. Structure and Infrastructure Engineering, 1-20, 2020 .

[11] L. Ierimonti, I. Venanzi, L. Caracoglia, A.L. Materazzi, Cost-Based Design of Nonstructural Element for Tall Buildings under Extreme Wind Environments. Journal of Aerospace Engineering, 32(3), 2019.

[12] I. Venanzi, R. Castellani, L. Ierimonti, F. Ubertini, An automated procedure for assessing local reliability index and life-cycle cost of alternative girder bridge solutions. Advances in Civil Engineering, 1-17, 2019. 
[13] S. Kunnath, Application of the PEER PBEE methodology to the I-880 viaduct. Rep. No. 2006/10. Davis, California: University of California.

[14] M. Miner, Cumulative damage in fatigue. Journal of Applied Mechanics, 12(3), 159-164, 1945.

[15] Eurocode 3, Design of steel structures-Part 1-9: Fatigue, Eurocode 3: EN 1993-1-9, Brussels, Belgium: European Committee for Standardization, 2005.

[16] S. D. Downing, D.F. Socie, Simple rainflow counting algorithms. Journal of Fatigue, 4(1), 31-40, 1982.

[17] Eurocode 1, Actions on structures-Part 2: Traffic load on bridges, Eurocode 1: EN 19912, Brussels, Belgium: European Committee for Standardization, 2003.

[18] Det Norske Veritas (DNV), Fatigue Design of Offshore Steel Structures. No. DNV-RPC203.

[19] M. Wicke, Inspection, assessment and maintenance. Proceedings of the 13th International Association of Bridge and Structural Engineering Congress on Challenges to Structural Engineering, Helsinki, Finland, Vol.2 pp.91-105, 1988.

[20] ANAS S.p.A., Listino prezzi 2020. Prove, Indagini e Monitoraggio, 2020.

[21] R. Rackwitz, Optimization-the basis of code-making and reliability verification. Structural Safety, 22(1), 27-60, 2000. 